\title{
Hvordan forebygge residiverende urinveisinfeksjoner etter menopausen?
}

\author{
Den nasjonale faglige veilederen for antibiotikabruk i primærhelsetjenesten sier at metenamin eller lokale \\ østrogener kan ha en forebyggende effekt ved residiverende ukomplisert cystitt hos eldre kvinner og at konti- \\ nuerlig antibiotikaprofylakse bør unngås. Siden veilederen ikke gir konkrete råd om prioriteringsrekkefølge \\ eller oppfølging, ønsker vi her å problematisere valg av legemiddel og diskutere hvordan behandlingen kan \\ skje i praksis.
}

\author{
Wenche Haugen \\ Olav Spigset \\ olav.spigset@legemidler.no
}

Residiverende urinveisinfeksjoner defineres som tre eller flere tilfeller med urinveisinfeksjoner i løpet av et år. Postmenopausale kvinner er spesielt utsatt $(1,2)$. Infeksjonene forårsakes i opp mot $80 \%$ av tilfellene av Escherichia coli. Andre vanlige bakterietyper er Enterococcus faecalis, Klebsiella pneumoniae og Proteus mirabilis. I sykehjem opptrer E. coli, Klebsiella og Proteus hyppigst, hvorav sistnevnte utgjør $10 \%(1,3)$. Antibiotikaresistens er et økende problem. I Norge er omtrent $20 \%$ av E. coli-isolatene fra urinprøver resistente mot trimetoprim (4).

En norsk prevalensstudie fra 2011 fant at $18 \%$ av i alt 1473 sykehjemsbeboere fikk forebyggende behandling for urinveisinfeksjon (5). Av dem som fikk behandling brukte $74 \%$ ett middel og $26 \%$ to eller flere midler. Det vanligste preparatet var metenamin (48\%), fulgt av vitamin C (32\%), peroralt østrogen $(21 \%)$, tranebær $(10 \%)$, vaginalt østrogen $(9 \%)$, trimetoprim $(5 \%)$ og nitrofurantoin (4\%) (5). En av fem av dem som fikk metenamin i denne studien ble også behandlet med vitamin C (Jenny Bergmann, personlig meddelelse). Forbruket $\mathrm{i}$ den generelle befolkningen på denne indikasjonen er ikke mulig å angi for andre midler enn metenamin, siden de andre midlene også brukes på andre indikasjoner. For metenamin tilsvarer salget $i$ Norge at rundt regnet 1 av 300, eller ca. 17000 individer, bruker midlet til enhver tid. Hvis situasjonen i den generelle befolkningen tilsvarer den på sykehjem, kan man anta at rundt halvparten av alle med residiverende urinveisinfeksjoner behandles med metenamin, de øvrige med andre midler. Er dette en rasjonell fordeling?

\section{Hvor god er dokumentasjonen?}

Cochrane-gruppen har publisert systematiske litteraturgjennomganger og metaanalyser for metenamin, østrogener, antibiotika og tranebær som profylakse ved residiverende urinveisinfeksjoner hos ulike pasientgrupper, inklusive postmenopausale kvinner (6-9). Generelt påpekes det at originalstudiene har betydelige metodologiske mangler (åpne eller enkeltblindede studier med uortodokse inklusjonskriterier, tvilsomme randomiseringsprosedyrer og uklare endepunkter). Dessuten er mange studier gamle og har få pasienter inkludert. Dermed blir effektestimatene i Cochrane-gjennomgangene tilsvarende usikre. Litteraturgjennomgangene på området konkluderer gjerne med at det trengs flere, større og bedre designede studier, men slike utsagn er ikke til hjelp i den kliniske hverdagen. Hvis man skal kreve store, veldesignede og konklusive studier før man gir noen form for behandling, kan det føre til behandlingsnihilisme. En mer pragmatisk tilpasning kan være å forsøke å gi et legemiddel selv om nytteeffekten er mer uklar, men da med større risiko for at ulempene, for eksempel i form av bivirkninger, overstiger den eventuelle nytten.

\section{Hva viser studiene?}

I Cochrane-gjennomgangen av metenamin (6) inngår det tre studier utført hos ikkegravide kvinner med residiverende urinveisinfeksjoner. I disse har effekten av metenamin vært svært konsistent: i metenamingruppene var 55-66\% residivfrie i hele oppfølgingsperioden, sammenliknet med $25-37 \%$ i placebogruppene. Ut fra dette kan antall pasienter som må behandles for at én skal få effekt (number needed to treat, NNT) beregnes til noe over 3. I den tilhørende metaanalysen (6) er det beregnet en relativ risiko for residiv på 0,24 ut ifra de studiene som inkluderte pasienter med ukompliserte urinveisinfeksjoner uansett årsak, men med et svært bredt $95 \%$-konfidensintervall: $0,07-0,89$.
I Cochrane-gjennomgangen av lokale østrogener (7) identifiserte man kun to små studier. I den ene studien, som var åpen, var den relative risikoen for residiv ved bruk av vaginalinnlegg med østradiol 0,64 . I den andre studien, som var dobbeltblind, var den relative risikoen for residiv ved bruk av østriol vaginalkrem 0,25 . Igjen var konfidensintervallene vide, henholdsvis $0,47-0,86$ og 0,13-0,50. Data spriker så mye at det ikke er meningsfullt å beregne noen NNT-verdi. Den betydelige usikkerheten i disse tallene gjenspeiles $i$ at Cochrane konkluderer med at vaginalt østrogen kan være et relevant valg og at BMJ Best Practice anbefaler bruken (10), mens UpToDate ikke har dette alternativet med i sine anbefalinger (11).

Effekten av peroralt østrogen ble av Cochrane (7) vurdert ut ifra fire studier. Her fant man ingen effekt sammenliknet med placebo.

Den nyeste Cochrane-gjennomgangen av tranebærprodukter, fra 2012, konkluderer med at slike midler ikke kan anbefales for å forebygge urinveisinfeksjoner (8). Dette avviker fra tidligere systematiske gjennomganger, der man har funnet en viss effekt av tranebær. Endringen skyldes inklusjon av en rekke nye studier, ikke minst en stor studie som ble publisert i 2011 og som ikke kunne påvise noen effekt (12).

I Cochrane-gjennomgangen av kontinuerlig antibiotikaprofylakse fant man at effekten var klart bedre enn placebo, med en NNT-verdi på 2 (9). Effekten av antibiotika var også bedre enn for de øvrige behandlingsalternativene, men en slik tolkning av data må gjøres med stor forsiktighet, siden det er gjort ytterst få studier som direkte har sammenliknet to aktive behandlingsformer. I den eneste dobbeltblindede studien der antibiotika er sammenliknet med metenamin (13), var det noen færre residiv i gruppen som fikk trimetoprim $100 \mathrm{mg} / \mathrm{d}(10 \%)$ og nitrofurantoin $75 \mathrm{mg} / \mathrm{d}(25 \%)$ enn i gruppen som fikk metenamin (34\%). Det er imidlertid ikke presentert noen styrkeberegning, og 


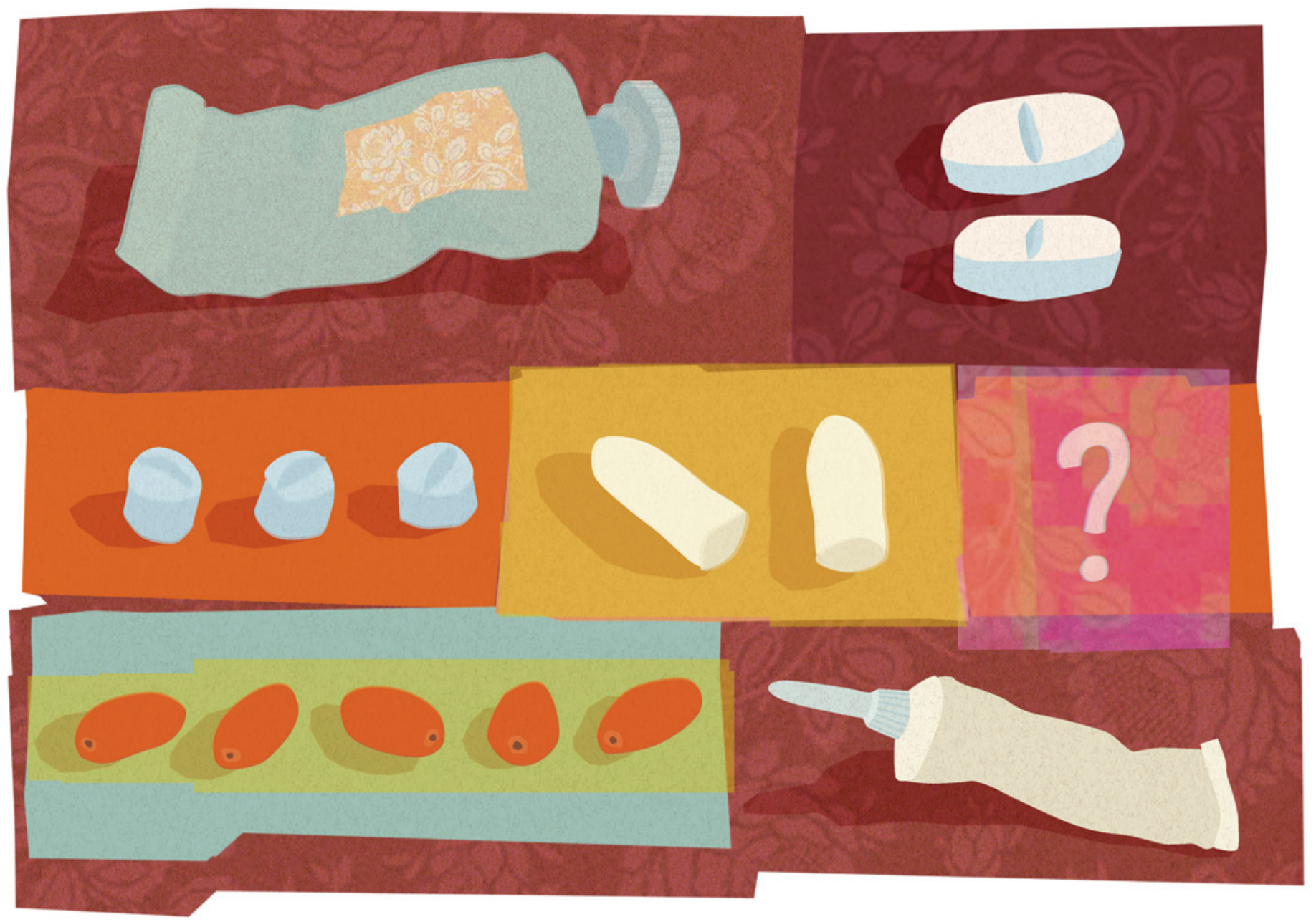

Illustrasjon @ Stein Løken

forskjellene er ikke signifikanstestet. To studier der lokalt østrogen ble sammenliknet med antibiotika (nitrofurantoin, ofloksacin) har gitt motstridende resultater $(14,15)$. Vi har ikke funnet studier der metenamin er sammenliknet med lokalbehandling med østrogen.

Hvis man velger å stole på ovenstående resultater, er det rimelig klart at kontinuerlig antibiotikaprofylakse virker bedre enn de andre behandlingsalternativene - $\mathrm{i}$ alle fall innenfor det tidsperspektivet som er studert, dvs. i hovedsak opptil ett år. Kan det likevel finnes grunner til å foretrekke noen av de andre midlene, som både er dårligere dokumentert og ser ut til å ha mindre effekt?

\section{Ulemper}

Antibiotikaresistens er et økende problem og jo mer antibiotika som brukes, jo større andel av bakteriene vil bli resistente. I Norge er omtrent $20 \%$ av E. coli-isolatene fra urinprøver allerede resistente mot trimetoprim (4). I en fersk studie der man hadde gitt tri- metoprim-sulfametoksazol som profylakse mot urinveisinfeksjon i ett år, fant man at mer enn $90 \%$ av isolatene av E. coli både fra urinveiene og fra feces var resistente mot trimetoprim (og trimetoprim-sulfametoksazol), mot knapt $30 \%$ før oppstart (16). Man kan dermed ikke uten videre gå ut fra at effekten av kontinuerlig antibiotikaprofylakse vil vedvare over tid hos en og samme pasient. Tre måneder etter avsluttet behandling var fortsatt rundt $60 \%$ av isolatene resistente (14). Slike tall bør mane til sterk tilbakeholdenhet med antibiotika som profylakse.

Cochrane-analysen viser at flere pasienter får bivirkninger med antibiotika enn med andre behandlingsformer, med en relativ risiko på 1,78 (95\% KI 1,06-3,00). I hovedsak var det gastrointestinale og vaginale bivirkninger som dominerte. Metenamin har på den annen side få og som oftest lette bivirkninger. Det er lav systemisk absorpsjon av vaginalt applisert østrogen, men i de studiene som inngikk i Cochrane-gjennomgangen ble det likevel rapportert økt forekomst av ømme bryster. I tillegg ble det sett lokale bivirkninger i form av sporblødninger og utflod fra vagina samt irritasjon, svie og kløe i underlivet. Det er også en rekke kontraindikasjoner og forsiktighetsregler som det må tas hensyn til i forbindelse med lokal østrogenbehandling.

Nitrofurantoin forutsetter tilnærmet normal nyrefunksjon for å oppnå adekvat konsentrasjon i urinveiene. Heller ikke trimetoprim eller metanamin vil gi optimal effekt ved nedsatt nyrefunksjon. Lokalbehandling med østrogen stiller på den annen side ingen krav til nyrefunksjon for effekt.

Metenamin er tilgjengelig i form av metenaminhippurat, som spaltes til metenamin og hippursyre. I urin omdannes metenamin til formaldehyd, som virker ved å denaturere bakterienes enzymer. Dermed vil det ikke oppstå resistens mot midlet. Omdanningen til formaldehyd er imidlertid avhengig av $\mathrm{pH}$, som ikke bør være over 5,5-6,0 for at bakteriostatiske konsentrasjoner skal oppnås $(16,17)$. Vanligvis er urinen lett sur, og hippursyren vil også bidra til å opprettholde en tilstrekkelig lav $\mathrm{pH}$. Siden P. mira- 
bilis og Pseudomonas aeruginosa spalter urinbestanddeler til basiske stoffer, vil dette øke $\mathrm{pH}$ og kunne redusere effekten av metenamin.

Det er ikke helt uvanlig at metenamin kombineres med vitamin $\mathrm{C}$ for å surgjøre urinen. Effekten av vitamin $\mathrm{C}$ som surgjørende middel er svak. Man må trolig opp i doser på 5-6 g for å få en påvisbar reduksjon i $\mathrm{pH}$, og selv da er effekten ytterst beskjeden $(18,19)$. Slike høye doser vitamin $\mathrm{C}$ er dessuten forbundet med bivirkninger som diaré og nyrestein.

\section{Hva skal man gjøre i praksis?}

Siden metenamin og lokale østrogener i motsetning til antibiotika ikke er omfattet av noen resistensutvikling og har lite bivirkninger, vil et av disse midlene etter vår oppfatning være det mest rasjonelle valget ved langtidsbehandling av residiverende urinveisinfeksjoner hos postmenopausale kvinner. I valget mellom disse tilsier tilgjengelig dokumentasjon - selv om den er svak - at metenamin forsvarer sin plass som førstevalg. Metenamintablettene er store og kan være vanskelig å svelge for noen, men de kan knuses, og preparatet finnes også tilgjengelig som dosepulver. Ved manglende effekt av metenamin foreslår vi at $\mathrm{pH}$ $\mathrm{i}$ urinen måles. Bruk av vitamin $\mathrm{C}$ vil ikke senke $\mathrm{pH}$-verdien nevneverdig. Hvis verdien ikke er tilstrekkelig lav, bør metenamin seponeres og behandling med lokalt østrogen overveies. Det samme gjelder når nyrefunksjonen er så redusert at metenamin ikke skilles ut i tilstrekkelige mengder $i$ urinen. Hos kvinner med betydelige symptomer på lokal østrogenmangel vil behandling med vaginalt østrogen være et logisk førstevalg. På den annen side vil applisering av østrogenkrem to ganger ukentlig og ikke minst det å sette inn og ta ut en østradiolring være problematisk for eldre kvinner.

Hvis effekten av det ene midlet er utilstrekkelig, bør man overveie å bytte til det andre såfremt det ikke er spesielle grunner som taler mot det. Det finnes ikke data som sier noe om nytten av kombinasjonsbehandling med metanamin og lokaltvirkende østrogen. Først når begge disse terapialternativene har sviktet eller ikke kan brukes av andre årsaker, er det etter vår oppfatning naturlig å overveie profylakse med trimetoprim eller nitrofurantoin. Tranebær og peroralt østrogen kan ikke forventes å ha noen positiv effekt.

\section{Wenche Haugen (f. 1971)}

er spesialist i allmennmedisin, arbeider i allmennpraksis og har bistilling som universitetslektor ved Norges teknisk-naturvitenskapelige universitet. Hun har tidligere hatt forskningsstillinger.

Forfatter har fylt ut ICMJE-skjemaet og oppgir ingen interessekonflikter.

\section{Olav Spigset (f. 1963)}

er spesialist i klinisk farmakologi, overlege ved Avdeling for klinisk farmakologi, St. Olavs hospital og professor ved Norges teknisk-naturvitenskapelige universitet.

Forfatter har fylt ut ICMJE-skjemaet og oppgir ingen interessekonflikter.

\section{Litteratur}

1. Foxman B. The epidemiology of urinary tract infec tion. Nat Rev Urol 2010; 7: 653-60.

2. Helsedirektoratet. Nasjonale faglige retningslinjer for antibiotikabruk i primærhelsetjenesten, 2013 http://helsedirektoratet.no/publikasjoner/ nasjonale-faglige-retningslinjer-forantibiotikabruk-i-primerhelsetjenesten/Sider/ default.aspx (19.8.2014).

3. Schmiemann G, Gágyor I, Hummers-Pradier E et al. Resistance profiles of urinary tract infections in general practice-an observational study. BMC Urol 2012; 12: 33

4. NORM/NORM-vet 2012. Usage of antimicrobial agents and occurence of antimicrobial resistance in Norway. Tromsø/Oslo: Veterinærinstituttet, 2013.

5. Bergman J Schjøtt J, Blix HS. Prevention of urinary tract infections in nursing homes: lack of evidence-based prescription? BMC Geriatr 2011; 11: 69 .

6. Lee BS, Bhuta T, Simpson JM et al. Methenamine hippurate for preventing urinary tract infections. Cochrane Database Syst Rev 2012: 10: CD003265.

7. Perrotta C, Aznar M, Mejia R et al. Oestrogens for preventing recurrent urinary tract infection in postmenopausal women. Cochrane Database Syst Rev 2008; nr. 2: CD005131.

8. Jepson RG, Williams G, Craig JC. Cranberries for preventing urinary tract infections. Cochrane Database Syst Rev 2012; 10: CD001321.

9. Albert X. Huertas I, Pereiró II et al. Antibiotics for preventing recurrent urinary tract infection in non-pregnant women. Cochrane Database Syst Rev 2004; nr. 3: CD001209.

10. BMJ Best Practice. Urinary tract infections in women. Treatment options. http://bestpractice.bmj.com/best-practice/ monograph/77/treatment/details.html\#expsec463984 (23.9.14)

11. UpToDate. Recurrent urinary tract infection in women. www.uptodate.com/contents/recurrenturinary-tract-infection-in-women? source= search_result\&search=recurrent+urinary+tract+ infection+in+females \& selectedTitle=1\%7E150 (23.9.2014)

12. Barbosa-Cesnik C, Brown MB, Buxton M et al. Cranberry juice fails to prevent recurrent urinary tract infection: results from a randomized placebo-controlled trial. Clin Infect Dis 2011; 52 . $23-30$

13. Kasanen A, Junnila SY, Kaarsalo E et al. Secondary prevention of recurrent urinary tract infections. Comparison of the effect of placebo, methenamine hippurate, nitrofurantoin and trimethoprim alone. Scand J Infect Dis 1982; 14: 293-6.

14. Raz R, Colodner R, Rohana Y et al. Effectiveness of estriol-containing vaginal pessaries and nitrofurantoin macrocrystal therapy in the prevention of recurrent urinary tract infection in postmenopausal women. Clin Infect Dis 2003; 36: 1362-8

15. Xu R, Wu Y, Hu Y. Prevention and treatment of recurrent urinary system infection with estrogen cream in postmenopausal women. Zhonghua Fu Chan Ke Za Zhi 2001: 36: 531-3.

16. Beerepoot MAJ, ter Riet G, Nys S et al. Lactobacilli vs antibiotics to prevent urinary tract infections: a randomized, double-blind, noninferiority trial in postmenopausal women. Arch Intern Med 2012 172: $704-12$

17. Statens legemiddelverk. Hiprex. www.legemiddelverket.no/Legemiddelsoek/Sider/ Legemiddelvisning.aspx?pakningld=79cea4a51882-4b80-af64-f6549cf8bd6d\&searchquery= hiprex\&f=Han;Mtl;Vir;ATC;Var;Mar;Mid;Avr;\& pane $=0(19.8 .2014)$

18. Strom JG Jr, Jun HW. Effect of urine $\mathrm{pH}$ and ascorbic acid on the rate of conversion of methenamine to formaldehyde. Biopharm Drug Dispos 1993; 14 $61-9$

19. Baxmann AC, De O G Mendonça C, Heilberg IP. Effect of vitamin $\mathrm{C}$ supplements on urinary oxalate and $\mathrm{pH}$ in calcium stone-forming patients. Kidney Int 2003: 63: 1066-71.

Mottatt 25.8. 2014, første revisjon innsendt 26.9. 2014, godkjent 3.10. 2014. Redaktør: Are Brean. 